Hydroacoustic simulation of rotor-stator interaction in resonance conditions in Francis pumpturbine

This article has been downloaded from IOPscience. Please scroll down to see the full text article. 2010 IOP Conf. Ser.: Earth Environ. Sci. 12012005

(http://iopscience.iop.org/1755-1315/12/1/012005)

View the table of contents for this issue, or go to the journal homepage for more

Download details:

IP Address: 128.178.4.133

The article was downloaded on 23/02/2011 at 15:04

Please note that terms and conditions apply. 


\title{
Hydroacoustic simulation of rotor-stator interaction in resonance conditions in Francis pump-turbine
}

\author{
C Nicolet ${ }^{1}$, N Ruchonnet ${ }^{2}$, S Alligné ${ }^{2}$, J Koutnik ${ }^{3}$ and F Avellan ${ }^{2}$ \\ ${ }^{1}$ Power Vision Engineering sàrl, Ch. des Champs-Courbes 1, CH-1024 Ecublens, \\ Switzerland ${ }^{2}$ EPFL Laboratory for Hydraulic Machines, Av. de Cour 33bis, CH-1007 \\ Lausanne, Switzerland \\ ${ }^{3}$ Voith Hydro Holding GmbH \& Co. KG, Alexanderstr. 11, 89522 Heidenheim, Germany \\ E-mail: christophe.nicolet@powervision-eng.ch
}

\begin{abstract}
Combined effect of rotating pressure field related to runner blade and wakes of wicket gates leads to rotor stator interactions, RSI, in Francis pump-turbines. These interactions induce pressures waves propagating in the entire hydraulic machine. Superposition of those pressure waves may result in standing wave in the spiral casing and rotating diametrical mode in the guide vanes and can cause strong pressure fluctuations and vibrations. This paper presents the modeling, simulation and analysis of Rotor-Stator Interaction of a scale model of a Francis pump-turbine and related test rig using a one-dimensional approach. The hydroacoustic modeling of the Francis pump-turbine takes into account the spiral casing, the 20 guide vanes, the 9 rotating runner vanes. The connection between stationary and rotating parts is ensured by a valve network driven according to the unsteady flow distribution between guide vanes and runner vanes. Time domain simulations are performed for 2 different runner rotational speeds in turbine mode. The simulation results are analyzed in frequency domain and highlights hydroacoustic resonance between RSI excitations and the spiral case. Rotating diametrical mode in the vaneless gap and standing wave in the spiral case are identified. The influence of the resonance on phase and amplitude of pressure fluctuations obtained for both the spiral case and the vaneless gap is analyzed. The mode shape and frequencies are confirmed using eigenvalues analysis.
\end{abstract}

\section{Introduction}

Hydraulic pump-turbine operating under steady state conditions are subject to pressure fluctuations resulting from the interaction between the rotating and the stationary parts of the machine known as Rotor-Stator Interaction. This is the consequence of modulation between the potential flow perturbations caused by the impeller blades and the flow perturbations caused by the guide vanes wake. These interactions induce pressure waves propagating in the entire hydraulic machine and may lead to two different kinds of pressure fluctuations in the machine :

- diametrical pressure mode rotating in the vaneless gap between the guide vane and the impeller blades, see Boller [1], or Ohura et al.[2];

- standing waves in the spiral casing, see Chen[3] and Dörfler [4].

The diametrical modes may cause hydromechanics resonance between the rotating diametrical pressure mode and the structure of impeller, see Tanaka [5] or of the head cover and may induce strong vibrations, noise, fissures or guide vanes bearing ruins, see Fisher et al. [6]. The standing wave may cause resonance with the power house structure that generates unacceptable vibrations and noise [2]. The standing wave phenomenon may also lead to pressure fluctuations in the penstock as it was early identified by Den Hartog [7] and also reported by Dörfler [4].

The prediction of such phenomena enables to select appropriate guide vanes and blade combination during the early stage of the design of a reversible pump-turbine. Some analytical models have been developed by Bolleter [1] and Ohura et al. [2] for the diametrical mode shape and by Chen [3] and Dörfler [4] for the standing wave allowing for the prediction of the risk of occurrence of these phenomena. The prediction of the occurrence of the standing wave is based on the analysis of the traveling time of pressure waves propagating in a one-dimensional system modeling the pump-turbine accordingly to its topology. Recently, Haban et al. [8] have developed more sophisticated 
one-dimensional models based on matrix transfer method that have shown their capability of predicting spiral casing standing wave patterns. By the use of such models Fischer et al. [6] have pointed out the link between the standing waves in the spiral casing and the penstocks and the diametrical pressure mode rotating in the vaneless gap by performing a forced response analysis in the frequency domain. However this approach requires the identification of the excitation pattern by the method described by Bolleter [1] and Tanaka et al. [2]. Therefore, Nicolet et al. [9] developed a RSI hydroacoustic models including a simplified model of the excitation source based on a valve network between stationary and rotating parts driven according to the flow distribution in the vaneless gap.

Using the same simulation model, the influence of resonance conditions between the diametrical modes and standing wave in spiral case are investigated first by means of time domain simulations. The influence of resonance conditions on the diametrical mode shape and standing wave pattern is presented. Then, the mode shapes are compared with the results of eigenvalue analysis.

\section{Hydroacoustic modeling}

By neglecting the convective terms $C \partial / \partial x$ and assuming plane pressure wave and uniform velocity field in a cross section, the momentum and the continuity equations established for the pipe of a length $d x$, a cross section $A$ and a wave speed $a$, reduces to the hyperbolic partial differential equations, see Wylie and Streeter Error! Reference source not found.] :

$$
\frac{\partial h}{\partial t}+\frac{a^{2}}{g A} \cdot \frac{\partial Q}{\partial x}=0, \quad \frac{\partial h}{\partial x}+\frac{1}{g A} \cdot \frac{\partial Q}{\partial t}+\frac{\lambda|Q|}{2 g D A^{2}} \cdot Q=0
$$

Where the $h$ and $Q$ variables are the piezometric head and the discharge, respectively. The system of hyperbolic equations (1) is solved using Finite Difference Method considering a $1^{\text {st }}$ order centered scheme discretization in space and a Lax scheme for the discharge, see Nicolet [11]. This approach leads to a system of ordinary differential equations that can be represented as a T-shaped electrical equivalent scheme. The simulation models of hydraulic components based on equivalent scheme representation are implemented in the simulation software SIMSEN developed by EPFL, see [11]. In this software, the system of equations is set-up using Kirchoff laws and time domain integration of the full system is achieved by a Runge-Kutta $4^{\text {th }}$ order procedure. The global equation set is also linearized for eigenvalue analysis purpose, see Alligné et al [13].

\section{Pump-turbine modeling and RSI patterns}

\subsection{Test case modeling}

The pump-turbine scale model considered in this investigation features a specific speed $v=0.17$ and low pressure diameter of $\mathrm{D}_{\text {ref }}=0.4 \mathrm{~m}$ and is installed on the test rig PF3 of the EPFL Laboratory for Hydraulic Machines. A full description of the model of this test rig can be found in [9]. The test rig is made of 2 feedings pumps in series, a piping system, the pump-turbine model itself and a downstream tank as presented Fig. 1. The pump-turbine features a 20 guide vanes and 9 runner vanes RSI arrangement. The mean wave speed in the spiral case is $1135 \mathrm{~m} / \mathrm{s}$ and the wave speed in guide vanes and runner vanes are $800 \mathrm{~m} / \mathrm{s}$. The operating condition for the simulation of the hydroacoustic behavior of the test rig corresponds to the nominal operating point without cavitation for a mean discharge of $0.23 \mathrm{~m}^{3} / \mathrm{s}$. The energy transfer from the fluid to the runner is modeled by a pressure source as function of the discharge $\mathrm{H}=\mathrm{H}(\mathrm{Q})$ which parameters are obtained by linearization of the pump-turbine characteristic. Each pipe of the spiral casing is modeled by 1 element, and each guide vane and impeller vane is modeled with 3 elements. The integration time step is set to $d t=85 \mu \mathrm{s}$, corresponding to less than $1.5^{\circ}$ of angular rotation of the runner for the maximum speed considered in this investigation. This discretization ensures a minimum of 10 points to represents a wavelength at frequency of $700 \mathrm{~Hz}$.

The model of the pump-turbine includes a model of the RSI excitation based on a valve network connecting the guide vanes to the runner vanes. Each guide vane is connected to each runner vane, thus 180 valves are driven according to the flow evolution between stationary and rotating parts. Full description of this modeling can be found in [9]. 

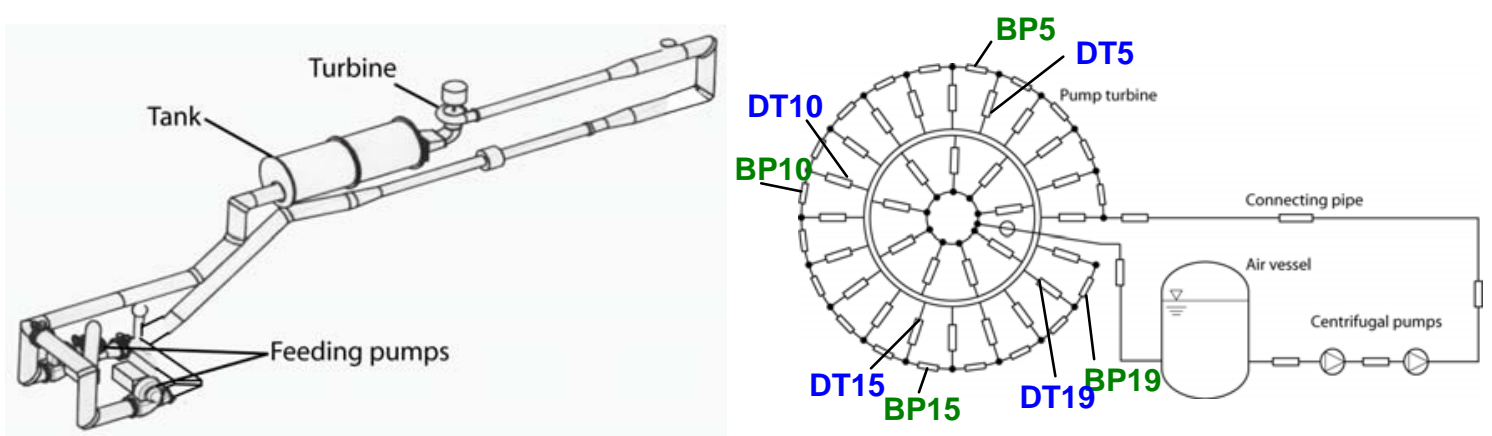

Fig. 1 PF3 test rig layout (left) and related hydroacoustic model (right)

\subsection{RSI patterns}

The flow field leaving the guide vane of a Francis pump-turbine in generating mode is characterized by the velocity defect caused by the guide vanes. The pressure field attached to the rotating impeller blade induces also incoming flow field distortions. These two periodic flow fields can be expressed as Fourier series. The resulting pressure field, combining the guide vanes and the impeller blade pressure field is characterized by a modulation process. Thus, the pressure in the area of the vaneless gap between the guide vanes and impeller blades can be expressed as the product of both rotating and stationary fields of pressure leading to the summation of every component. The resulting pressure field can be expressed in the stationary reference frame and gives, see Franke [14]:

$$
p_{m n}=\frac{A_{m n}}{2} \cos \left(m Z_{b} \omega t-\left(m Z_{b}-n Z_{o}\right) \theta_{s}+\phi_{n}-\phi_{m}\right)+\frac{A_{m n}}{2} \cos \left(m Z_{b} \omega t-\left(m Z_{b}+n Z_{o}\right) \theta_{s}-\phi_{n}-\phi_{m}\right)
$$

Where $Z_{b}$ is the number of impeller blades, $Z_{o}$ is the number of guide vanes, $m$ and $n$ are respectively the order of the harmonic in the runner and in the guide vanes, $A_{m n}$ is the combined amplitude from harmonic $m$ and $n$ and $\theta_{s}$ is the angular position in the stationary frame. This pressure field represents 2 diametrical pressure modes having the following numbers of minima and maxima:

$$
k_{1}=m \cdot Z_{b}-n \cdot Z_{o} \text { and } k_{2}=m \cdot Z_{b}+n \cdot Z_{o}
$$

rotating with the respective spinning speed in the stationary frame of reference:

$$
\omega_{1}=m Z_{b} \omega_{b} / k_{1} \text { and } \omega_{2}=m Z_{b} \omega_{b} / k_{2} \text {. }
$$

Furthermore, the sign of the diametrical mode numbers $\mathrm{k} 1$ and $\mathrm{k} 2$ indicates that the diametrical mode is rotating in the same direction as the impeller when positive and counter-rotating when negative. It is also important to notice that lower amplitudes are expected for higher $\mathrm{k}$ values, because of the high harmonic number. As a result, k2 is usually not relevant. The RSI patterns of the pump-turbine are determined analytically using relations (2), (3) and (4), according to its rotor-stator arrangement and are reported in Table 1.

Table 1 RSI patterns of the pump-turbine $\left(Z_{o}=20 ; Z_{b}=9\right)$

\begin{tabular}{|r|r|r|r|r|r|r|r|r|r|}
\cline { 4 - 9 } & \multicolumn{4}{c}{} & \multicolumn{3}{|c|}{ Stationary Frame } & \multicolumn{3}{|c|}{ Rotating Frame } \\
\hline \hline$n$ & $m$ & $k_{1}$ & $k_{2}$ & $\omega_{1} / \omega_{b}$ & $\omega_{2} / \omega_{b}$ & $f / f_{b}$ & $\omega_{2}{ }^{1} / \omega_{b}$ & $\omega_{2}{ }^{1} / \omega_{b}$ & $f / f_{b}$ \\
\hline & & $m Z_{b}-n Z_{o}$ & $m Z_{b}+n Z_{o}$ & $m Z_{b} / k 1$ & $m Z_{b} / k 2$ & $m Z_{b}$ & $n Z_{o} / k 1$ & $n Z_{o} /-k 2$ & $n Z_{o}$ \\
\hline 1 & 2 & -2 & 38 & -9.0 & 0.5 & 18 & -10.0 & 0.5 & 20 \\
\hline 2 & 4 & -4 & 76 & -9.0 & 0.5 & 36 & -10.0 & 0.5 & 40 \\
\hline
\end{tabular}

This investigation focuses on the diametrical mode with the lowest value $\mathrm{k}_{1}=-2$ which pressure pattern with two pressure maxima and two pressure minima. This counter-rotating pressure mode features a rated frequency in the stationary frame of two times the blade passing frequency, BPF, given by $f / f_{b}=2 \times Z_{b}=18$. 


\section{Analytical analysis of spiral casing standing wave}

If the diametrical mode of $\mathrm{k}_{1}=-2$ is considered, and according to Pulpitel et al. [15], one can estimate the natural frequency of the standing wave in the spiral casing having the same pressure pattern with two maxima and two minima with a wave length of:

$$
\lambda_{s p}=\frac{\pi \cdot D_{s p}}{|k|}=\frac{\pi \cdot D_{s p}}{2}
$$

Where $\pi D_{s p}$ is the developed length of the spiral case. Knowing the wave speed $a_{s p}$ in the spiral case, the corresponding frequency is defined by:

$$
f_{s p}=\frac{a_{s p}}{\lambda_{s p}}=\frac{a_{s p} \cdot 2}{\pi \cdot D_{s p}}
$$

The frequency of the pressure fluctuations induced by the diametrical mode in the stationary frame is given by:

$$
f=f_{b} m Z_{b}=m \cdot B P F=2 \cdot B P F
$$

Where BPF is the blade passing frequency. Resonance condition is reached if the frequency of the diametrical mode is equal to the estimated natural frequency of the spiral case $f=f s p$ :

$$
2 B P F=\frac{a_{s p} \cdot 2}{\pi \cdot D_{s p}}
$$

The general form of the resonance conditions derived by Chen [3] is obtained by the combination of equations (3), (4) and (6) and given by:

$$
\frac{a_{s p}}{\pi D_{s p}}=\frac{m Z_{b} f_{b}}{\left|m Z_{b}-n Z_{o}\right|}
$$

Considering the mean waves speed of the spiral case of the pump-turbine scale model estimated to be $1^{\prime} 135 \mathrm{~m} / \mathrm{s}$, and the developed length of the spiral case of $3.06 \mathrm{~m}$, the resonance frequency related to the diametrical mode $\mathrm{k}_{1}=-2$ is equal to:

$$
2 B P F=\frac{a_{s p} \cdot 2}{\pi \cdot D_{s p}}=\frac{1135 \cdot 2}{3.06}=742 \mathrm{~Hz}
$$

\section{Time domain simulation analysis}

Time domain simulations are performed with the hydroacoustic model presented in Fig. 1 right, considering first out of resonance condition and then resonance condition by adapting the runner rotational frequency $f_{b}$. For out of resonance conditions, and according to the resonance frequency estimated to be $742 \mathrm{~Hz}$, the runner rotational frequency is set to $2 B P F=700 \mathrm{~Hz}$. Analysis of the pressure fluctuations in the spiral case obtained from the simulation with $2 B P F=700 \mathrm{~Hz}$, enabled to identify that the natural frequency of the full hydroacoustic model corresponding to the diametrical mode $\mathrm{k}_{1}=-2$ is $2 B P F=762 \mathrm{~Hz}$. The value of the natural frequency of the hydroacoustic model differs from the value obtained with the analytical expression (8), because it accounts for realistic boundary conditions instead of idealized conditions. Then, time domain simulation is also performed for resonance condition given by $2 B P F=762 \mathrm{~Hz}$. The amplitude spectra of the pressure fluctuations obtained at 4 different locations, see locations BP5, BP10, BP15 and BP19 in Fig. 1 right, in the spiral case for out of resonance $(2 B P F=700 \mathrm{~Hz})$ and resonance conditions $(2 B P F=762 \mathrm{~Hz})$ are presented in

Fig. 2. Pressure amplitude spectra in the guide vane close to the vaneless gap are computed and represented for 4 different locations, see locations DT5, DT10, DT15 and DT19, in Fig. 1 right, for out of resonance and resonance conditions in Fig. 3. The blade passing frequency and its harmonics are also indicated in

Fig. 2 and in Fig. 3.

As expected, for both cases $2 * \mathrm{BPF}=700 \mathrm{~Hz}$ and $2 * \mathrm{BPF}=762 \mathrm{~Hz}$, there is significant pressure amplitudes spectra in the spiral case and in the guide vanes at the blade passing frequency and its harmonics resulting from the unsteady flow distribution between stationary and rotating parts complying with the pump-turbine RSI arrangements. Moreover, as the excitation source is not sinusoidal, it provides energy on a wide frequency range and thus also reveals the hydroacoustic natural frequencies of the system pointed out by high amplitudes in the pressure amplitude spectra. The natural frequency of particular interest is visible in the spiral case at a frequency of $762 \mathrm{~Hz}$, which corresponds to the mode shape featuring the same pressure patterns as the diametrical mode $\mathrm{k}_{1}=-2$ with two maxima 
and two minima. Thus, the amplification of a factor above 10 of the pressure fluctuations at the frequency $2 * \mathrm{BPF}=762 \mathrm{~Hz}$ in case of resonance is clearly visible in Fig. 2 bottom. The pressure amplitudes spectra in the guide vanes shows reduced amplitudes for some natural frequencies visible in the spiral case, but also a natural frequency at $1194 \mathrm{~Hz}$ with high amplitudes.

The amplitude and phase of pressures in the spiral case and in the guide vane, are represented for $2 * \mathrm{BPF}=700 \mathrm{~Hz}$ and $2 * \mathrm{BPF}=762 \mathrm{~Hz}$ in Fig. 4 and in Fig. 5 respectively as function of the node number for the frequency $2 * \mathrm{BPF}$. The node number 1 is located at the spiral case inlet and node number 19 is located at the tongue. In Fig. 4 right, the phase distribution clearly evidences the pressure patterns of the diametrical mode of $\mathrm{k} 1=-2$, with a total phase shift of $2 *(2 * \pi)$ characterizing 2 pressure minima and maxima rotating opposite to the runner rotation. The amplitude in the guide vane is not constant because it is modulated by the pressure pattern in the spiral case. In the spiral case, the pressure amplitudes are very low with a shape strongly influenced by the natural frequency at $762 \mathrm{~Hz}$. In

Fig. 5 left, the pressure mode shape related to the natural frequency at $\mathrm{f}=762 \mathrm{~Hz}$ features very large amplitudes and the typical phase shift of $\pi$ between two consecutive pressure maximums and also shows a maximum of pressure at the spiral case tongue. The pressure mode shape in the spiral case, strongly affects the pressure patterns in the guide vanes which shape results from superposition of the diametrical mode and the system natural frequency. Particularly, the rotating pattern characterized by the phase shift of $2 *(2 * \pi)$ is not visible while the pressure amplitudes features the same pressure pattern as the spiral case.

The pressure fluctuations in the pump-turbine have been filtered with band pass filter set at $700 \mathrm{~Hz}$ and $762 \mathrm{~Hz}$ for the simulations $2 * B P F=700 \mathrm{~Hz}$ and the simulation at $2 * B P F=762 \mathrm{~Hz}$ and represented according to the pumpturbine topology in Fig. 6 and in Fig. 7 respectively. In Fig. 6 , for $2 * B P F=700 \mathrm{~Hz}$, the diametrical mode $\mathrm{k}_{1}=-2$ is clearly visible while amplitudes in the spiral case are very low. In Fig. 7 , for $2 * B P F=762 \mathrm{~Hz}$ corresponding to resonance conditions, one may notice that the diametrical mode is not visible because of the very large amplitude of the standing wave taking place in the spiral case that imposes the pressure in the guide vanes.
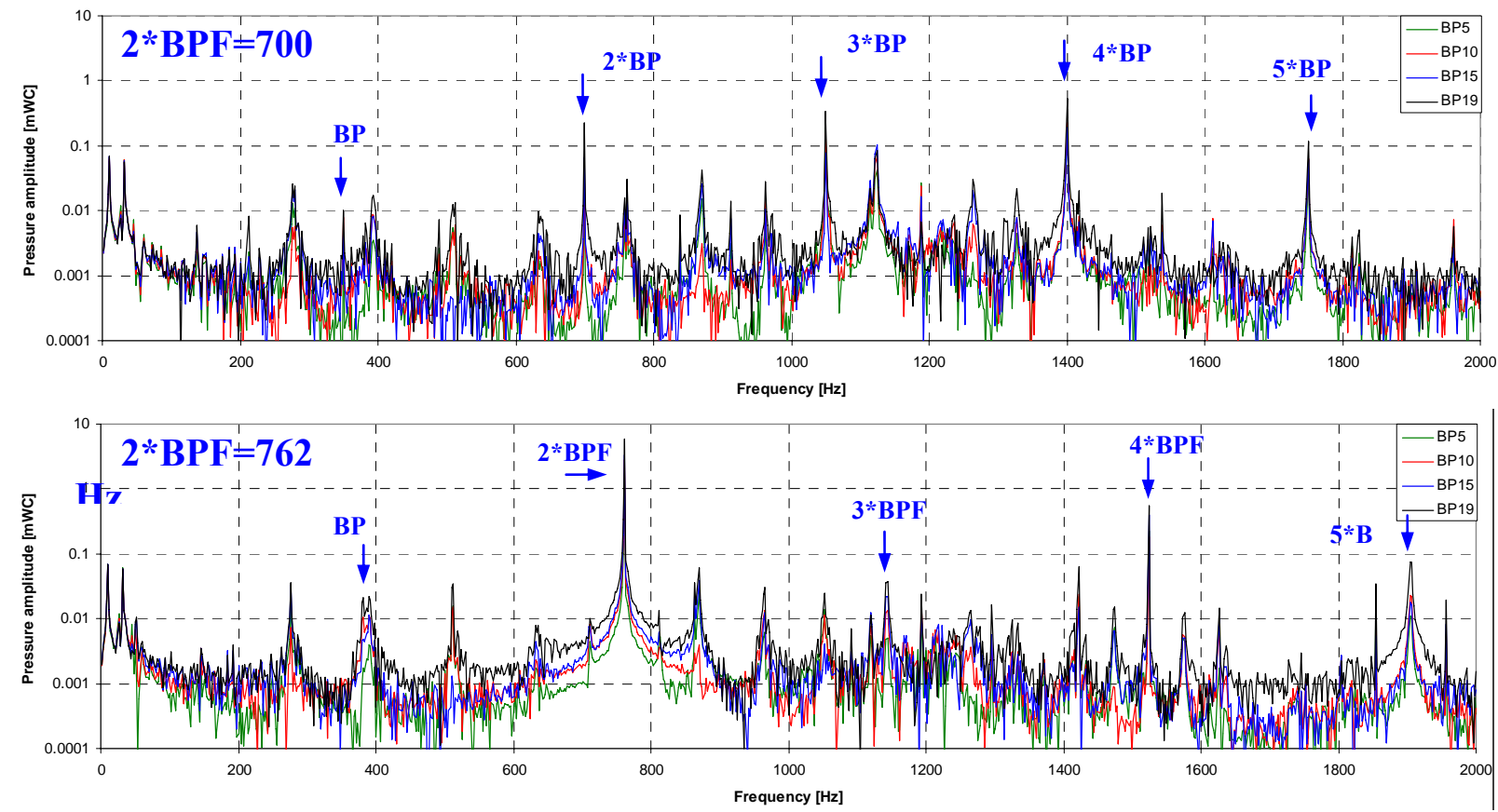

Fig. 2 Pressure amplitude spectra in the spiral case for locations BP5, BP10, BP15 and BP19, for $2 * \mathrm{BPF}=700$, out of resonance, (top) and $762 \mathrm{~Hz}$, in resonance (bottom) 

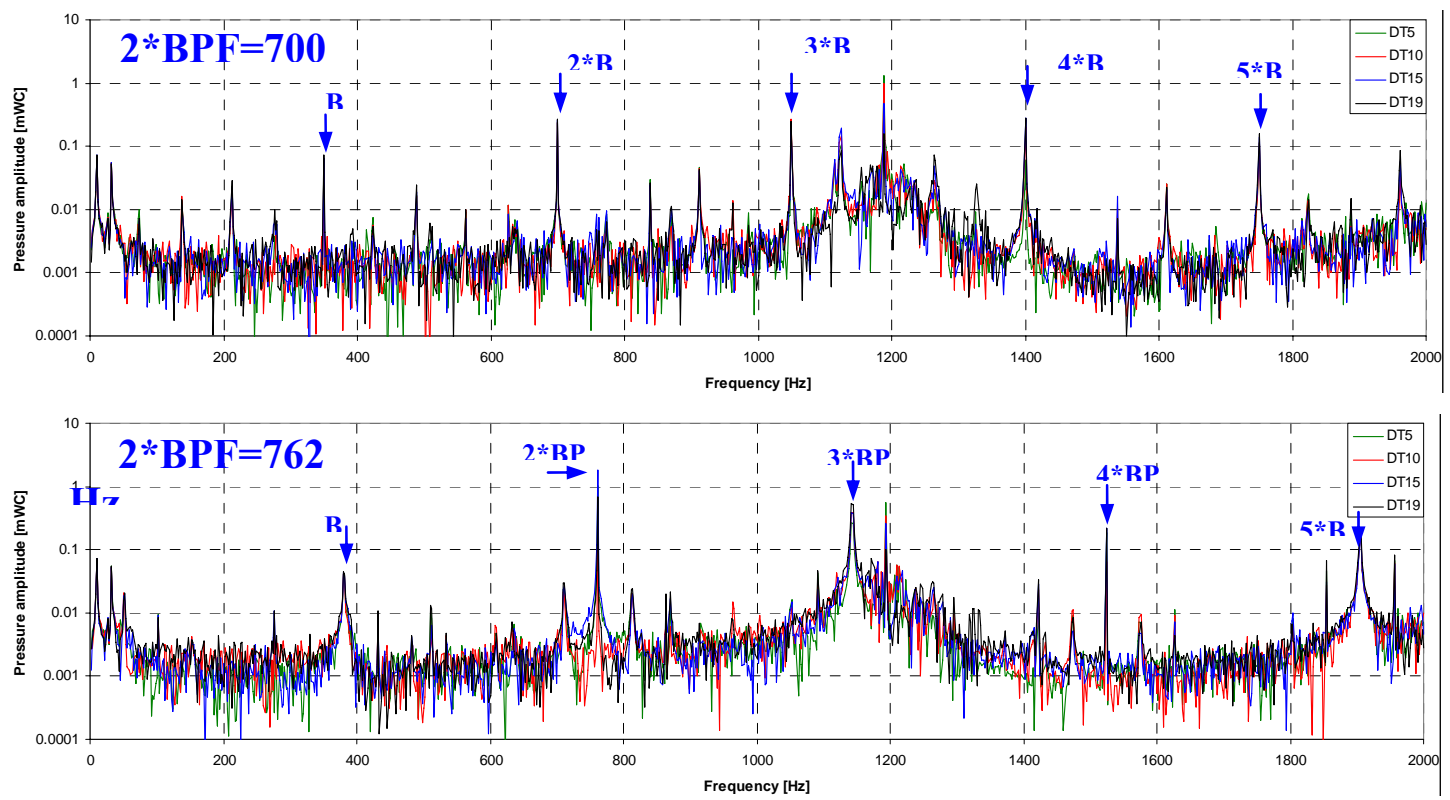

Fig. 3 Pressure amplitude spectra in the distributor channels for locations DT5, DT10, DT15 and DT 19, for $2 * \mathrm{BPF}=700$, out of resonance, (top) and $762 \mathrm{~Hz}$, in resonance (bottom)
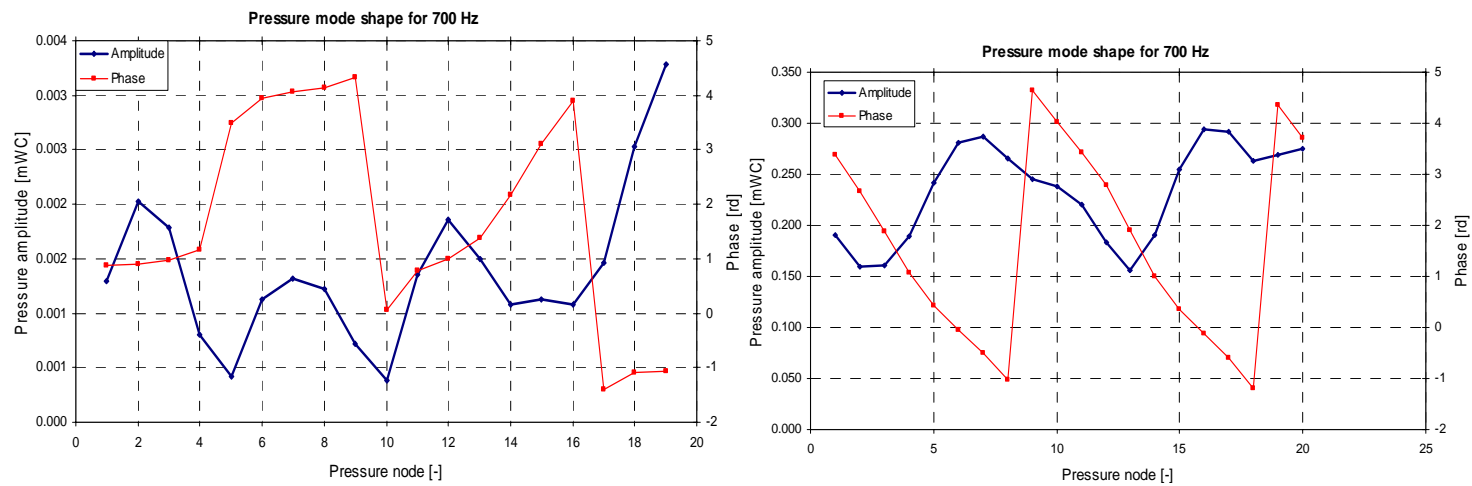

Fig. 4 Amplitude and phase of the pressure fluctuations at $2 * B P F=700 \mathrm{~Hz}$ in the spiral case (left) and in the guide vanes close to the vaneless gap (right) related to out of resonance condition
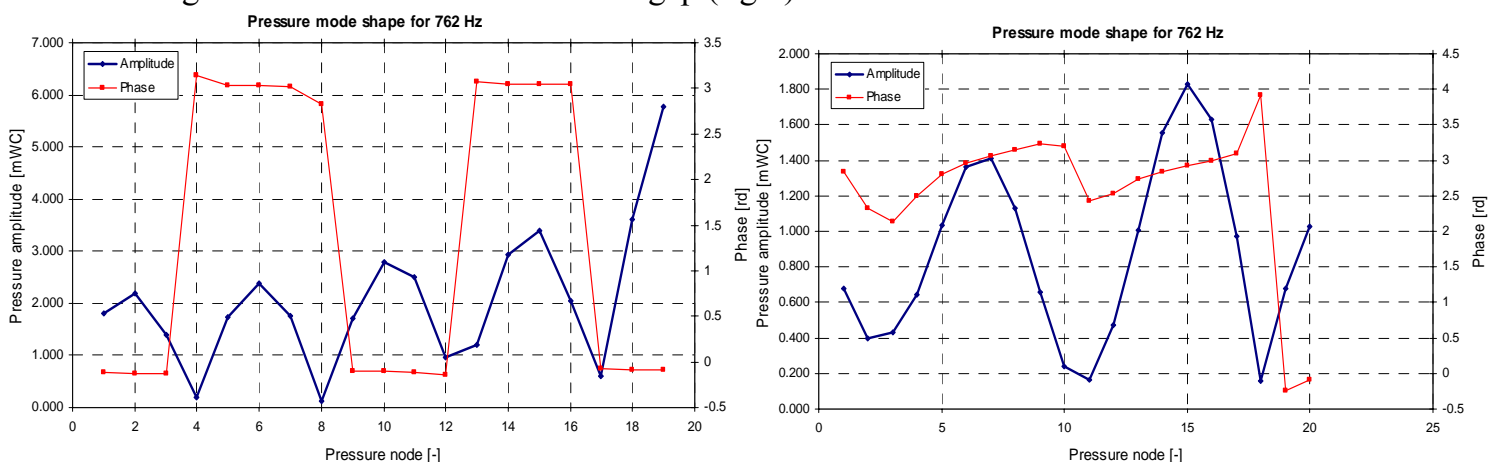

Fig. 5 Amplitude and phase of the pressure fluctuations at $2 * B P F=762 \mathrm{~Hz}$ in the spiral case (left) and in the guide vanes close to the vaneless gap (right) related to resonance condition 

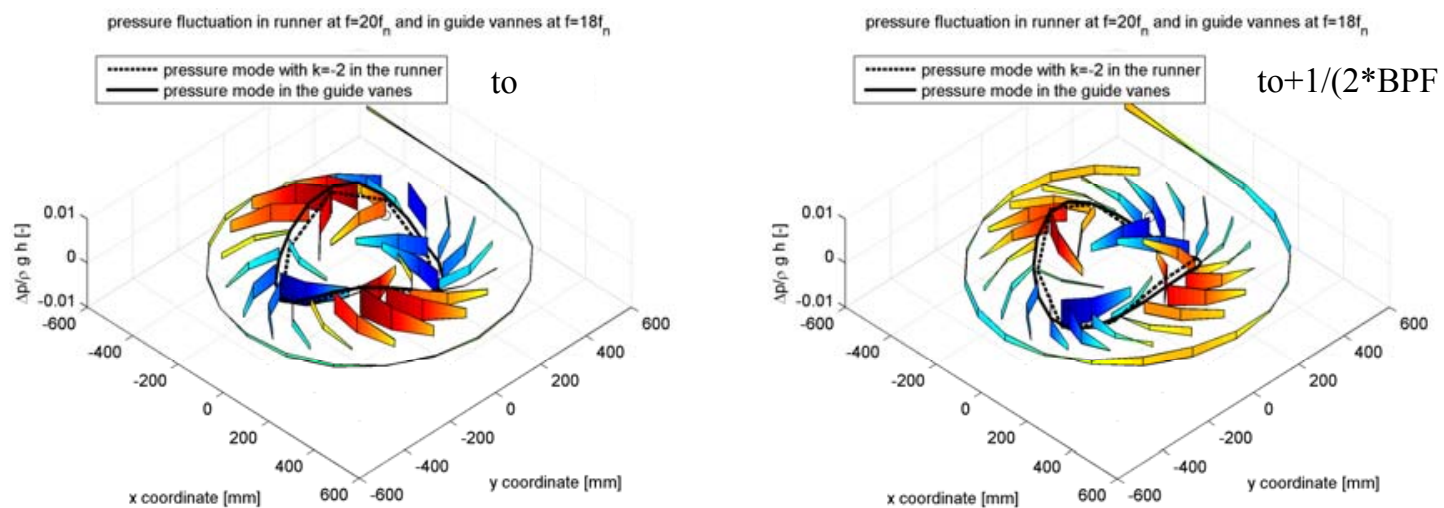

Fig. 6 Pressure amplitude in the pump-turbine for $2 * B P F=700 \mathrm{~Hz}$ out of resonance
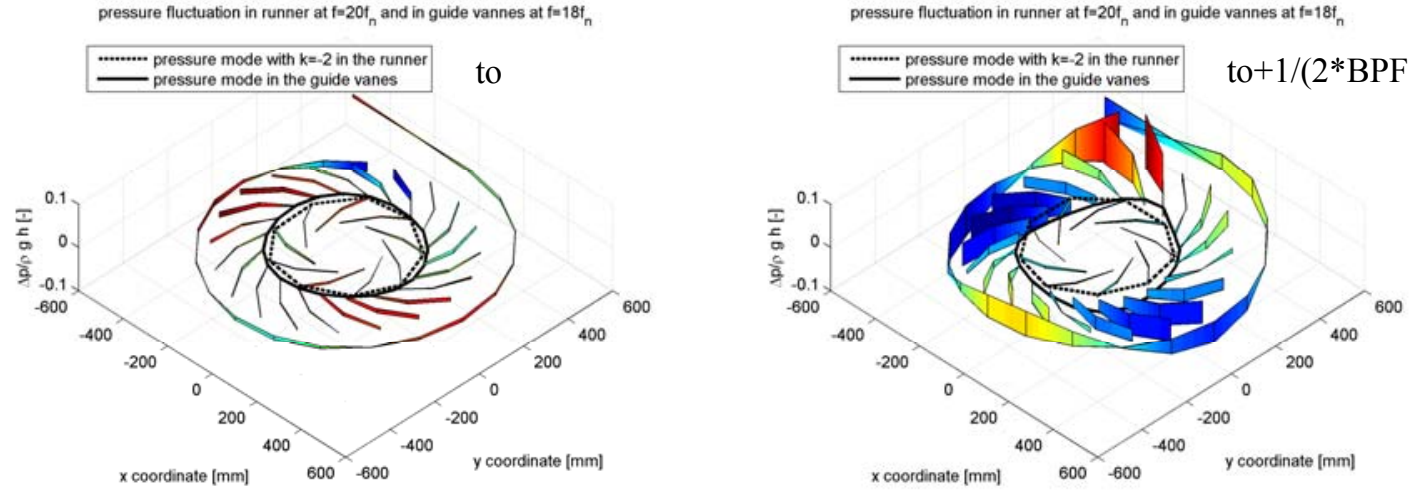

Fig. 7 Pressure amplitude in the pump-turbine for $2 * B P F=762 \mathrm{~Hz}$ in resonance conditions

\section{Eigenvalue analysis}

Eigenvalues of the hydroacoustic system are computed using SIMSEN after linearization of the global matrix according to Alligné et al., see [13]. For this computation, the hydraulic layout is simplified using only one valve connected to all the guide vanes with all the runner vanes. The valve head losses are set-up to obtain the correct total discharge in the hydraulic system. It has been verified that the eigenvalues obtained with the simplified model with one single valve are very close to the eigenvalues obtained with the 180 valves modeling the RSI excitation. The natural frequency of the system identified at $762 \mathrm{~Hz}$ is obtained at $761 \mathrm{~Hz}$ with the eigenvalue analysis and the corresponding eigenmode shape in the spiral case, guide vanes and runner vanes is presented in Fig. 8.

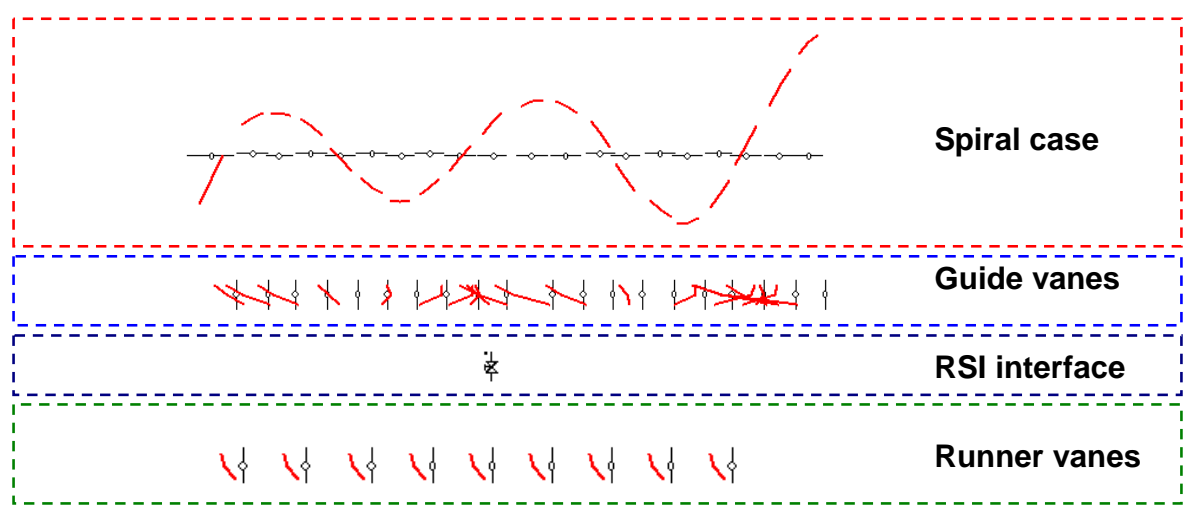

Fig. 8 Eigenmode shape of the hydroacoustic system at $f=761 \mathrm{~Hz}$

The values of the natural frequencies of the spiral case are estimated using analytical expression (6) and are summarized in Table 2. The values of natural frequencies related to the spiral case obtained from time domain simulation and from eigenvalues analysis are reported in Table 3. It can be noticed that if Mode A2 and Mode A4 
calculated with analytical expression show rather good agreement with the Mode H2 and Mode H6 obtained with the full hydroacoustic model, there is rather poor agreement for Mode A1 and Mode A3. Moreover, it can be noticed that the full hydroacoustic system exhibit larger number of natural frequencies related to the spiral case with Modes $\mathrm{H} 1$ to H6 instead of Modes A1 to A4. This difference is due to the influence of the hydraulic circuit that is not taken into account in the analytical expression and showing the shortcoming of such approach. The Table 4 presents the mode shape in spiral case and in guide vanes of the Mode H1, H3, H5 and H6 obtained from eigenvalue analysis.

Table 2 Natural frequency related to the spiral case estimated with analytical expression

\begin{tabular}{|c|c|c|c|c|}
\hline \hline Method & Mode A1 & Mode A2 & Mode A3 & Mode A4 \\
\hline $\begin{array}{c}\text { Analytical } \\
\text { calculation }\end{array}$ & $\frac{a_{s p}}{\pi \cdot D_{s p} \cdot 2}=185 \mathrm{H}$ & $\frac{a_{s p}}{\pi \cdot D_{s p}}=371 \mathrm{H}$ & $\frac{a_{s p} \cdot 3}{\pi \cdot D_{s p} \cdot 2}=556 \mathrm{H}$ & $\frac{a_{s p} \cdot 2}{\pi \cdot D_{s p}}=742 \mathrm{~Hz}$ \\
\hline
\end{tabular}

Table 3 Natural frequencies related to spiral case of the hydroacoustic model obtained with time domain simulation and eigenvalue analysis

\begin{tabular}{|c|c|c|c|c|c|c|}
\hline \hline Method & Mode H1 & Mode H 2 & Mode H 3 & Mode H 4 & Mode H 5 & Mode H 6 \\
\hline $\begin{array}{c}\text { Time domain } \\
\text { simulation }\end{array}$ & $280 \mathrm{~Hz}$ & $394 \mathrm{~Hz}$ & $512 \mathrm{~Hz}$ & $636 \mathrm{~Hz}$ & - & $762 \mathrm{~Hz}$ \\
\hline Eigenvalue analysis & $277 \mathrm{~Hz}$ & $391 \mathrm{~Hz}$ & $511 \mathrm{~Hz}$ & $635 \mathrm{~Hz}$ & $643 \mathrm{~Hz}$ & $761 \mathrm{~Hz}$ \\
\hline
\end{tabular}

Table 4 Eigenmode shape in the spiral case and the guide vanes

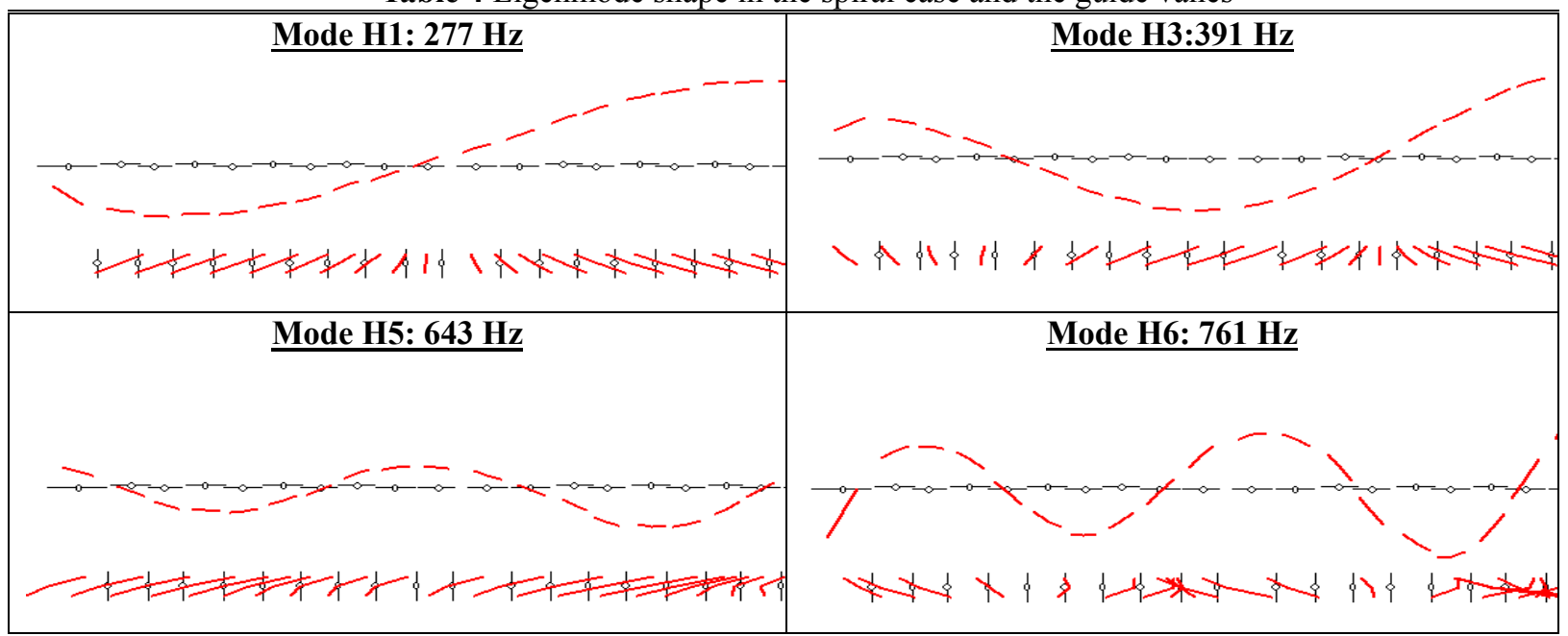

\section{Conclusion}

This paper presents the hydroacoustic modeling, simulation and analysis of a pump-turbine with 20 guide vanes and 9 runner vanes including a model of rotor stator excitation source based on flow distribution between stationary and rotating parts. The time domain simulations pointed out diametrical modes rotating in the vaneless gap and standing wave in the spiral case. Possible resonance between diametrical mode and the spiral case mode shape featuring same pattern is analyzed in terms of pressure amplitude and phase in spiral case and guide vanes and compared with the case out of resonance. It is pointed out that in case of resonance, the pressure patterns of the diametrical mode in the vaneless gap are dominated by the pressure patterns of the resonance. As the model of the excitation source is not purely sinusoidal, the time domain simulation also reveals all the natural frequencies relevant for RSI investigations. Estimations of natural frequencies based on simplified analytical expression are compared with natural frequencies obtained from time domain simulation and eigenvalue analysis. If some frequencies can be estimated with reasonable accuracy, some frequencies shows large discrepancies and some of them are basically not predicted. This difference is due to the influence of the hydraulic circuit representing complex boundary condition at the spiral case inlet which is properly taken into account in the full hydroacoustic model. Finally, eigenvalue analysis enabled to confirm natural frequencies identified with time domain simulation. 


\section{Nomenclature}

$\begin{array}{llll}A & \text { Cross Section Area, } \mathrm{m}^{2} & p & \text { Pressure, Pa. } \\ B P F & \text { Blade passing frequency } B P F=Z_{b} \cdot f_{b} & g & \text { Gravity Acceleration, } \mathrm{m} / \mathrm{s}^{2} \\ C & \quad \text { Absolute Mean Flow Speed, } \mathrm{m} / \mathrm{s}, & v & \text { Machine Specific Speed, } v=\omega \frac{(Q / \pi)^{1 / 2}}{(2 g H)^{3 / 4}} \\ & C=Q / A & \lambda & \text { Local Loss Coefficient } \\ D & \text { Pipe diameter, } \mathrm{m} & \rho & \text { Water Density, } \mathrm{kg} / \mathrm{m}^{3} \\ H & \text { Head, } \mathrm{m} & \omega_{b} & \text { Impeller Angular Speed, rad } / \mathrm{s} \\ Q & \text { Flow rate, } \mathrm{m}^{3} / \mathrm{s} Q=C \cdot A & n, m & \text { Harmonic Order } \\ D_{r e f} & \text { Machine Reference Diameter, } \mathrm{m} & Z_{o}, Z_{b} & \text { Number of Guide Vanes, impeller blades } \\ h & \text { Piezometric Head, } \mathrm{m}, h=z+p /(\rho g) & \theta_{s}, \theta_{r} \text { Angle in the Stationary, Rotating System } \\ a & \text { Wave Speed, } \mathrm{m} / \mathrm{s} & \phi_{n}, \phi_{m} & \text { Phase for the } \mathrm{n}^{\text {th }}, \mathrm{m}^{\text {th }} \text { Harmonic }\end{array}$

\section{References}

[1] Bolleter U 1988 Blade passage tones of centrifugal pump Vibrations 4(3) 8-13

[2] Ohura Y, Fujii M, Sugimoto O, Tanaka H and Yamagata I 1990 Vibration of the powerhouse structure of pumped storage power plant Proc. of the $15^{\text {th }}$ IAHR Symp. (Belgrade, Serbia)

[3] Chen Y N 1961 Water-Pressure Oscillations in the Volute Casings of Storage Pumps Sulzer Technical Review, Research Number 21-34

[4] Dörfler P 1984 On the phase role of phase resonance in vibrations caused by blade passage in radial hydraulic turbomachines Proc. $12^{\text {th }}$ IAHR Symp. (Stirling, UK) pp 227-241

[5] Tanaka H 1994 Special design considerations for ultra high head pump-turbines Hydropower \& Dams 107-112

[6] Fisher R, Powell C, Franke G, Seidel U and Koutnik J 2004 Contributions to the improved understanding of the dynamic behaviour of pump turbines and uses thereof in dynamic design Proc. $22^{\text {nd }}$ IAHR Symp. (Stockholm, Sweden) pp B11-3

[7] Den Hartog J P 1956 Mechanical vibrations $4^{\text {th }}$ edition (New York: McGraw-Hill) 7-9

[8] Haban V, Koutnik J and Pochyly F 2002 1-D Mathematical model of high-frequency pressure oscillations induced by RSI including an influence of fluid second viscosity Proc. $21^{\text {st }}$ IAHR Symp. (Lausanne, Switzerland) pp 735-740

[9] Nicolet C, Ruchonnet N and Avellan F 2006 One-Dimensional Modeling of Rotor Stator Interaction in Francis Pump-Turbine Proc. of ISROMAC-11, ASME: International Symp. on Transport Phenomena and Dynamics of Rotating Machinery (Honolulu, Hawaii, USA)

[10] Wylie E B and Streeter V L 1993 Fluid transients in systems (Prentice Hall, Englewood Cliffs, N.J.)

[11] Nicolet C 2007 Hydroacoustic Modelling and Numerical Simulation of Unsteady Operation of Hydroelectric Systems PhD Thesis EPFL n ${ }^{\circ} 3751$ Lausanne (http://library.epfl.ch/theses/?nr=3751)

[12] Paynter H M 1953 Surge and water hammer problems Transaction of ASCE 146 962-1009

[13] Alligné S, Nicolet C, Allenbach P, Kawkabani B, Simond J J and Avellan F 2008 Influence of the Vortex Rope Location of a Francis Turbine on the Hydraulic System Stability Proc. of the 24th IAHR Symp. on Hydraulic Machinery and Systems (Foz do Iguassu, Brazil) p 106

[14] Franke G, Powell C, Seidel U, Koutnik J and Fischer R 2005 On pressure mode shapes arising from rotor/stator interactions $J$. of Sound \& Vibration 14-18

[15] Pulpitel L, Vesely J and Mikulasek J 2009 Comments to vibrations and pressure oscillations induced by the rotor stator interaction in a hydraulic turbine Proc. of the 3rd IAHR International Meeting of the Workgroup on Cavitation and Dynamic Problems in Hydraulic Machinery and Systems (Brno, Czech Republic) 